\title{
Pay It forward: Strategies for Successful Implementation of Short-term Endocrine Surgical Mission
}

\author{
${ }^{1}$ Kristin L Long, ${ }^{2}$ Mark Cohen, ${ }^{3}$ Nancy Perrier
}

\begin{abstract}
Introduction: With increasing interest in humanitarian surgical efforts, numerous opportunities for specialized mission trips have developed. Extreme short-term surgical "blitzes" of specialist teams have offered much-needed surgical care but lack efforts for patient continuity and local sustainability. We sought to define characteristics that aid in the long-term success of short-term international surgical missions to better apply this insight toward future dedicated humanitarian endocrine surgical efforts.
\end{abstract}

Materials and methods: A broad search engine review identified 1,954 reports of medical and surgical missions. One hundred and sixty-six of these abstracts involved surgical missions from 2009 to 2014 with 24 articles including details of specific mission trips. We identified factors deemed essential for improving patient care and affecting local infrastructure for longterm sustainability and included our prospective experience with an endocrine surgery-specific mission trip for comparison.

Results: Of the 24 articles reviewed, missions went to Africa (9), North America (8), South America (5), and Asia (5). Factors for mission sustainability and success included the following: (a) ability to educate local physicians and trainees, (b) multiple return trips to the same location, and (c) formal pre-mission planning and site visits. Emerging interest is on optimizing patient outcomes and cost-effectiveness.

Conclusion: Short-term surgical missions require a local infrastructure for optimal patient outcomes. Sustainability hinges on education and involvement of local physicians and surgical trainees, pre-mission planning, and return trips to the same location. For endocrine surgical missions, preoperative evaluation and postoperative follow-up by the operating surgeon is important for optimizing performance and outcomes.

Keywords: Endocrine, Humanitarian surgery, International, Thyroid.

How to cite this article: Long $\mathrm{KL}$, Cohen M, Perrier $\mathrm{N}$. Pay It forward: Strategies for Successful Implementation of Short-term Endocrine Surgical Mission. World J Endoc Surg 2016;8(2):137-140.

Source of support: Nil

Conflict of interest: None

\footnotetext{
${ }^{1}$ Fellow, ${ }^{2}$ Associate Professor ${ }^{3}$ Professor

${ }^{1,3}$ Department of Surgical Oncology, University of Texas MD Anderson Cancer Center, Houston, Texas, USA

${ }^{2}$ Department of Surgery, University of Michigan, Ann Arbor Michigan, USA

Corresponding Author: Kristin L Long, Fellow, Department of Surgical Oncology, University of Texas MD Anderson Cancer Center, Houston, Texas, USA, Phone:+17137450599, e-mail: kllong@mdanderson.org
}

\section{INTRODUCTION}

For many years, the majority of global health initiatives have focused on prevention of communicable diseases and promotion of public health education. Surgical treatment of even the most basic pathologies has been largely neglected in public health, especially in low- and middleincome countries with resource-limited settings. ${ }^{1,2}$ This landscape is beginning to change, as evidenced by the prominent representation of surgical conditions and basic surgical interventions as the first volume in the newest edition of the World Bank's Disease Control Priorities. ${ }^{3}$

As interest in humanitarian surgical effort surges, numerous opportunities for specialized short-term mission trips have emerged. Extreme short-term surgical "blitzes" of specialist teams have offered much-needed surgical care but lack efforts for patient continuity and local sustainability. Because of this, highly specialized or focused shortterm mission trips have often been the subject of criticism. ${ }^{4}$ Additionally, many surgical outreach programs require volunteer surgeons to cover a very broad range of conditions, from general surgery to orthopedics to urology. ${ }^{5}$ Recognizing that many surgical procedures, including thyroidectomy, are known to have improved outcomes when performed by high-volume specialists, we sought to define characteristics that aid in the long-term success of short-term international surgical missions and better apply this insight toward future dedicated humanitarian endocrine surgical efforts. ${ }^{6}$

\section{MATERIALS AND METHODS}

A broad search engine review of articles from PubMed and Web of Science identified 1,954 reports of medical and surgical missions. To refine the search, articles specifically discussing surgical mission trips were selected; 387 of the initial 1,954 abstracts involved surgical missions and by limiting our search to articles published from 2009 to 2014, we selected a final group of 166 manuscripts. Of these, 24 articles included descriptive details of the specific mission trips (Flow Chart 1).

By analyzing these articles, we identified factors deemed essential for improving patient care and affecting local infrastructure for long-term sustainability. Additionally, we included our prospective experience with an endocrine surgery-specific mission trip for comparison purposes. 
Flow Chart 1: Study design and search criteria

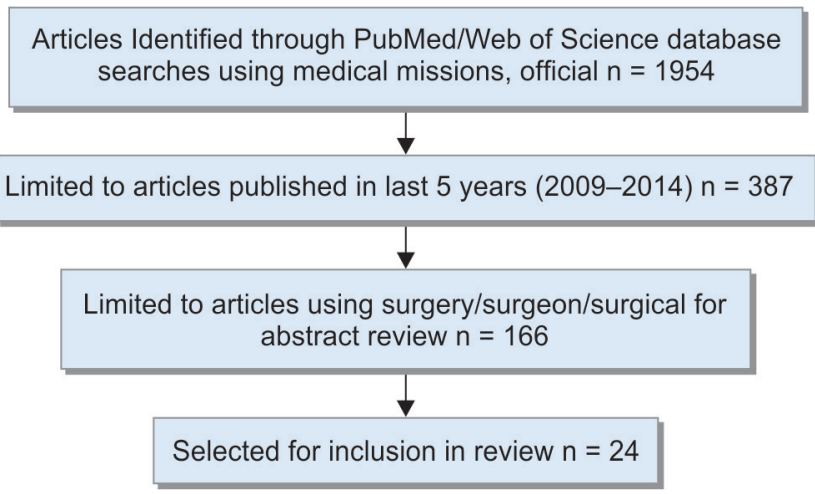

\section{RESULTS}

Of the 24 articles reviewed, mission trips were reported on 4 different continents. The majority went to Africa (9) ${ }^{7-15}$ North America (8), ${ }^{16-23}$ South America (5), ${ }^{9,21,24-26}$ and Asia $(5)^{9,27-30} ; 67 \%$ of these trips included surgical trainees, $42 \%$ were plastic surgery-focused, and 37\% were general/orthopedic surgery-focused (Graph 1). No manuscript detailed a mission trip specific to endocrine surgery. Trips lasted from 4 days to 3 weeks in length. Fifteen of the trips documented originated from the United States, four originated from the United Kingdom, and the remaining trips originated from Italy, Canada, Switzerland, and New Zealand.

The most commonly cited factors for mission sustainability and success across all articles included the following: (a) ability to educate local physicians and trainees, (b) multiple return trips to the same location, and (c) formal pre-mission planning and site visits. Within the world of global surgery, emerging interest is on optimizing patient outcomes and cost-effectiveness. These three aforementioned factors will undoubtedly help surgical mission trips achieve the lasting impact desired by many international volunteers.

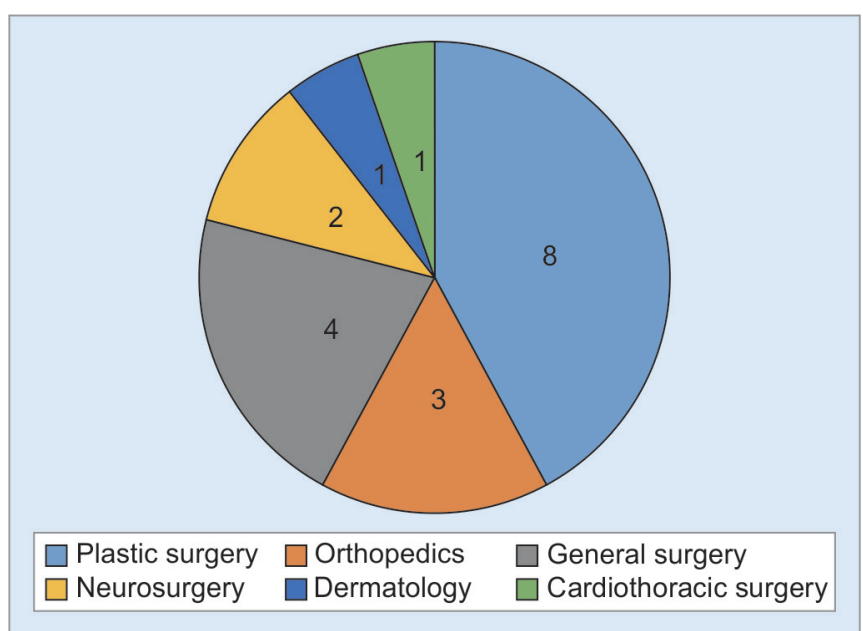

Graph 1: Most common surgical specialties represented in short-term mission trips
All authors participated in mission trips. One was a dedicated endocrine mission trip to Tanzania, another part of a long-term established general surgical trip with specific assignment to teaching and performing endocrine surgery. The trip to Tanzania (Dr. Mark Cohen) included 19 subtotal thyroidectomies performed over 5 days for symptomatic goiters. In its entirety, the trip lasted 10 days, which allowed for all potential operative patients to be evaluated for surgical suitability in a preoperative clinic on the first day at the facility. All patients were evaluated and examined by the operating surgeon, including a surgeon-performed neck ultrasound, prior to surgical intervention. Surgeries were performed on days 2 to 6 of the mission trip, and all patients were followed postoperatively until discharge. The last patient was discharged on day 9 of the trip. The staff present for this trip included one endocrine surgeon, one trauma/ general surgeon, two operating room nurses, a pediatric intensivist, and an anesthesiologist. The intensivist covered the postanesthesia recovery unit with a team of local nurses while the remainder of the visiting team was in the operating room.

Surgeries were typically performed from 8 am until $6 \mathrm{pm}$, as there was no backup generator for the lights after dark, a common occurrence in low-resource settings. Average operative time for subtotal thyroidectomies was 92 minutes ( \pm 18 minutes). All patients received a single 18 to 20 gauge peripheral intravenous line (PIV) and general endotracheal anesthesia (GETA) using isoflurane. No nerve monitoring devices were used. No energy device other than standard monopolar electrocautery was used.

Each patient was left with approximately $2 \mathrm{~cm}$ remnant of thyroid tissue at the trachea-esophageal groove bilaterally to preserve a euthyroid state postoperatively, given the lack of availability of thyroid hormone replacement. All patients had thyroid-stimulating hormone (TSH) levels checked 3 weeks postoperatively at the local facility lab to ensure adequate follow-up, with evidence of euthyroid levels in all patients.

A board-certified pathologist at the facility confirmed pathology as benign in all specimens. No postoperative complications (bleeding, recurrent laryngeal nerve injury, or hypocalcemia) were observed. No surgical drains were placed in any patient and no cases of postoperative infection were noted.

\section{DISCUSSION}

As humanitarian surgical missions benefit from increasing popularity and publicity, establishing a sustainable, cost-effective platform that promotes delivery of the highest quality surgical care is paramount. ${ }^{31}$ The technically demanding cases treated by endocrine surgeons offer 
a prime example of the need for specialist involvement in these endeavors. Many endocrinopathies also require a complex long-term medical management. These treatment plans may differ drastically in settings of low-resource or low-income countries. Awareness of these socioeconomic factors, which is gained by close interaction with local health care providers and sustained relationships with mission fields, allows for optimal patient care. In our particular experiences, no local surgeons were directly involved in the care of the patients undergoing surgical intervention for endocrine disease. We recognize this as a limitation of our experience and acknowledge the importance of working closely with facilities where local surgeons are available. Additionally, one-on-one training between visiting specialists and local surgeons to perform safe thyroid surgery adds a key element of sustainability to humanitarian surgery and should be encouraged whenever possible.

Treatment of pathologies, such as, Graves' disease often includes a total thyroidectomy in developed countries where access to lifelong thyroid hormone replacement poses no challenge. However, this medication may be unavailable or unaffordable for many patients in developing countries, and often results in knowledgeable surgeons offering subtotal thyroidectomy as the treatment of choice. ${ }^{32}$ A critical component, therefore, necessary to the ongoing success of endocrine surgery missionary efforts is establishing a local base of care with the ability to triage appropriate patients for surgery as well as a mechanism for patient follow-up after surgery.

As seen in our personal experience, as well as in the literature, many resource-poor countries are endemic goiter zones. ${ }^{33}$ Patients with minimal access to health care resources often present in very advanced stages of disease (Fig. 1). These cases are often challenging and are best served by surgeons experienced in the management

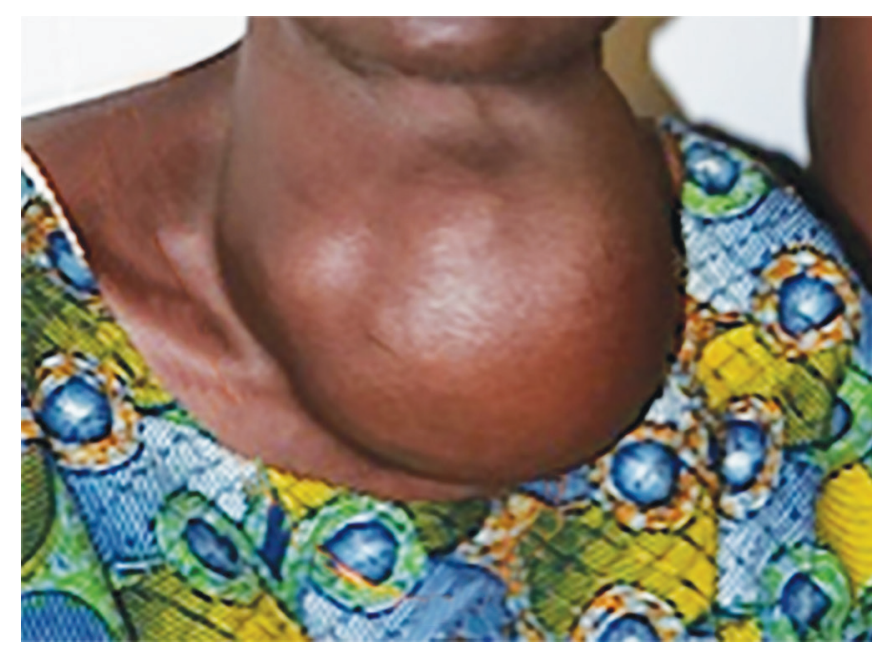

Fig. 1: Advanced thyroid pathology as seen in surgical mission trips to endemic goiter zones (Courtesy: Dr. Nancy Perrier) of complex thyroid disease. In fact, it has been well documented that outcomes and complication rates for complex thyroid surgeries are improved when performed by surgeons with specialized training in this area and higher volume practices.

As humanitarian surgical efforts continue to expand and offer increasingly sustainable surgical care to the developing world, we strongly advocate forming partnerships with mission hospitals in these locations. Developing a trustworthy relationship with local facilities and health care providers allows for a mutually beneficial experience for patients and providers alike. Consistent short-term visits to the same location foster a sense of trust and security in the care provided, as well as creating a forum for highly specialized experts to train local providers and improve care for patients with complex conditions. Specific to endocrine surgery, the council of the International Association of Endocrine Surgeons has developed Interest (International Endocrine Surgical Teams), which serves as an outreach program to provide support for endocrine surgical teaching, operative supervision, and equipment provision to developing countries. ${ }^{34}$ Additional resources, such as telemedicine may facilitate continuous involvement of the visiting surgeons and improve both patient follow-up and outcomes research. As has been the experience of each of the authors, humanitarian surgical mission work is tremendously fulfilling and when done appropriately offers a unique opportunity to pay it forward.

\section{REFERENCES}

1. Farmer PE, Kim JY. Surgery and global health: a view from beyond the OR. World J Surg 2008 Apr;32(4):533-536.

2. Grimes CE, Henry JA, Maraka J, Cotton M. Cost-effectiveness of surgery in low- and middle-income countries: a systematic review. World J Surg 2014 Jan;38(1):252-263.

3. Mock CN, Donkor P, Gawande A, Jamison DT, Kruk ME, Debas HT. Essential surgery: key messages from disease control priorities, 3rd ed. Lancet 2015 May;385(9983): 2209-2219.

4. Magee WP, Raimondi HM, Beers M, Koech MC. Effectiveness of international surgical program model to build local sustainability. Plast Surg Int 2012;2012:185725.

5. Chu K, Rosseel P, Trelles M, Gielis P. Surgeons without borders: a brief history of surgery at Médecins Sans Frontières. World J Surg 2010 Mar;34(3):411-414.

6. Kandil E, Noureldine SI, Abbas A, Tufano RP. The impact of surgical volume on patient outcomes following thyroid surgery. Surgery 2013 Dec;154(6):1346-1352.

7. Rockwell WT, Agbenorku P, Olson J, Hoyte-Williams PE, Agarwal JP, Rockwell WB. A model for university-based international plastic surgery collaboration builds local sustainability. Ann Plast Surg 2015 Apr;74(4):388-391.

8. McClenaghan F, Fell M, Martin D, Smith G, McGurk M. Surgical mission planning in the developing world. Int J Oral Maxillofac Surg 2013 Dec;42(12):1587-1591. 
9. Semplicini A, Vindigni V, Giatsidis G, Chiarelli A. Padova Hospitale Onlus: report of a 15-year experience in surgical and medical assistance in developing countries. Ann Plast Surg 2013 Jul;71(1):6-9.

10. Grimes CE, Maraka J, Kingsnorth AN, Darko R, Samkange CA, Lane RH. Guidelines for surgeons on establishing projects in low-income countries. World J Surg 2013 Jun;37(6): 1203-1207.

11. Cousins GR, Obolensky L, McAllen C, Acharya V, Beebeejaun A. The Kenya orthopaedic project: surgical outcomes of a travelling multidisciplinary team. J Bone Joint Surg Br 2012 Dec;94(12):1591-1594.

12. Kim GJ, Wedderburn RV, Ibanga I. Short-term surgical missions make a difference: a life-changing case in Ibi, Nigeria. Bull Am Coll Surg 2012 Nov;97(11):31-35.

13. deBuys Roessingh AS, Dolci M, Zbinden-Trichet C, Bossou R, Meyrat BJ, Hohlfeld J. Success and failure for children born with facial clefts in Africa: a 15-year follow-up. World J Surg 2012 Aug;36(8):1963-1969.

14. Hujiing MA, Marck KW, Combes J, Mizen KD, Fourie L, Demisse Y, Befikadu S, McGurk M. Facial reconstruction in the developing world: a complicated matter. Br J Oral Maxillofac Surg 2011 Jun;49(4):292-296.

15. Calisti A, Belay K, Mazzoni G, Fiocca G, Retrosi G, Olivieri C. Promoting major pediatric surgical care in a low-income country: a 4-year experience in Eritrea. World J Surg 2011 Apr;35(4):760-766.

16. Kavolus JJ, Ritter MA, Claverie JG, Barfield WR, Lackland DT, Trousdale RT. Concerns for an itinerant surgeon: results of a Guatemalan surgical aid trip. J Arthroplasty 2014 May;29(5): 861-866.

17. Withers $\mathrm{M}$, Browner $\mathrm{CH}$, Agbaloo T. Promoting volunteerism in global health: lessons from a medical mission in Northern Mexico. J Community Health 2013 Apr;38(2):374-384.

18. Ramirez-Fort MK, Lastra-Vicente R, Levitt JO, Sanchez JL, Reizner GT. Organizing a dermatology service mission. Int J Dermatol 2013 Mar;52(3): 342-349.

19. Chen AT, Pedtke A, Kobs JK, Edwards GS Jr, Coughlin RR, Gosselin RA. Volunteer orthopedic surgical trips in Nicaragua: a cost-effectiveness evaluation. World J Surg 2012 Dec;36(12): 2801-2808.

20. Sykes KJ, Le PT, Sale KA, Nicklaus PJ. A 7-year review of the safety of tonsillectomy during short-term medical mission trips. Otolaryngol Head Neck Surg 2012 May;146(5):752-756.

21. Walk RM, Glaser J, Marmon LM, Donahue TF, Bastien J, Safford SD. Continuing promise 2009 - assessment of a recent pediatric surgical humanitarian mission. J Pediatr Surg 2012 Apr;47(4):652-657.
22. Belvansky I, Williams KB, Gashti M, Heitmiller RF. Surgical relief work in Haiti: a practical resident learning experience. J Surg Educ 2011 May-Jun;68(3):213-217.

23. Chin-Quee A, White L, Leeds I, MacLeod J, Master VA. Medical student surgery elective in rural Haiti: a novel approach to satisfying clerkship requirements while providing surgical care to an underserved population. World J Surg 2011 Apr;35(4):739-744.

24. MacIntosh RB, Herman LT, Shivapuia PK, Echeverri-Arguello RC. Volunteer cleft surgery in Colombia: an 18-year experience. J Oral Maxillofac Surg 2013 Oct;71(10):1742-1751.

25. Duenas VJ, Hahn EJ, Aryan HE, Levy MV, Jandial R. Targeted neurosurgical outreach: 5-year follow-up of operative skill transfer and sustainable care in Lima, Peru. Childs Nerv Syst 2012 Aug;28(8):1227-1231.

26. Adam C, Kiefer P, Ryan K, Smith D, McCabe G, Allen P, Sridhar K, Torres $\mathrm{P}, \mathrm{Chu}$ MW. Humanitarian cardiac care in Arequipa Peru: experiences of a multidisciplinary Canadian cardiovascular team. Can J Surg 2012 Jun;55(3):171-176.

27. Patel A, Sawh-Martinez RF, Sinha I, Watkins JF, Magee WP, Persing JA. Establishing sustainable international burn missions: lessons from India. Ann Plast Surg 2013 Jul;71(1): 31-33.

28. Moon W, Perry H, Baek RM. Is international volunteer surgery for cleft lip and cleft palate a cost-effective and justifiable intervention? A case study. World J Surg 2012 Dec;36(12): 2819-2830.

29. Davis PJ, Wainer Z, O'Keefe M, Nand P. Cardiac surgery in the Pacific Islands. ANZ J Surg 2011 Dec;81(12): 871-875.

30. Hack J, Pieper D. Craniofacial/neurosurgery: a multidisciplinary approach to the repair of meningoencephaloceles in a third world country. J Neurosci Nurs 2011 Aug;43(4):E6-E9.

31. Shrime MG, Sleemi A, Ravilla TD. Charitable platforms in global surgery: a systematic review of their effectiveness, cost-effectiveness, sustainability, and role training. World J Surg 2015 Jan;39(1):10-20.

32. Donohoe NO, Kintu-Luwaga R, Bolger J, Odubu Fualal J. A prospective analysis of thyroidectomy outcomes in a resource-limited setting. World J Surg 2015 Jul;39(7): 1708-1711.

33. Baxi M, Shetty KJ, Baxi J, Basu A, Talwar OP, Smithi S, Tiwari PK, Maudar KK. Need for an individualized and aggressive management of multinodular goiters of endemic zones by specially trained surgeons: experience in Western Nepal. World J Surg 2006 Dec;30(12):2101-2109.

34. International Association of Endocrine Surgeons website [accessed 2015 Aug 14]. Available from: http://www.iaesendocrine-surgeons.com/pdf/14interest.pdf. 